\title{
Alaskan Bog Blueberry (Vaccinium uliginosum) Extract as an Innovative Topical Approach to Prevent UV-Induced Skin Damage
}

\author{
Erika Pambianchi ${ }^{1} \mathbb{D}$, Zachary Hagenberg ${ }^{1}$, Alessandra Pecorelli ${ }^{1} \mathbb{D}$, Mary Grace $^{2} \mathbb{D}$, Jean-Philippe Therrien ${ }^{2} \mathbb{D}$, \\ Mary Ann Lila ${ }^{2}$ (D) and Giuseppe Valacchi $1,3,4, *$ (D) \\ 1 North Carolina Research Campus, Plants for Human Health Institute, Animal Science Department, \\ North Carolina State University, Kannapolis, NC 28081, USA; epambia@ncsu.edu (E.P.); \\ zahagenb@ncsu.edu (Z.H.); apecore@ncsu.edu (A.P.) \\ 2 North Carolina Research Campus, Plants for Human Health Institute, Food, Bioprocessing \& Nutrition \\ Sciences Department, North Carolina State University, Kannapolis, NC 28081, USA; \\ mhgrace@ncsu.edu (M.G.); jtherri2@ncsu.edu (J.-P.T.); mlila@ncsu.edu (M.A.L.) \\ 3 Department of Environment and Prevention, University of Ferrara, 44121 Ferrara, Italy \\ 4 Department of Food and Nutrition, Kyung Hee University, Seoul 02447, Korea \\ * Correspondence: gvalacc@ncsu.edu
}

check for updates

Citation: Pambianchi, E.; Hagenberg, Z.; Pecorelli, A.; Grace, M.; Therrien, J.-P.; Lila, M.A.; Valacchi, G. Alaskan Bog Blueberry (Vaccinium uliginosum) Extract as an Innovative Topical Approach to Prevent UV-Induced Skin Damage. Cosmetics 2021, 8, 112. https://doi.org/10.3390/cosmetics 8040112

Academic Editor: Enzo Berardesca

Received: 4 November 2021

Accepted: 26 November 2021

Published: 27 November 2021

Publisher's Note: MDPI stays neutral with regard to jurisdictional claims in published maps and institutional affiliations.

Copyright: (c) 2021 by the authors. Licensee MDPI, Basel, Switzerland. This article is an open access article distributed under the terms and conditions of the Creative Commons Attribution (CC BY) license (https:// creativecommons.org/licenses/by/ $4.0 /)$.

\begin{abstract}
Our body is continuously exposed to various exogenous aggressors, and, in particular, the skin represents the main target for outdoor stressors, including ultraviolet (UV) radiation. UV exposure is well-known to be associated with the development/worsening of extrinsic photoaging and a multitude of skin conditions. Considering the role of photoprotection in skin health, the research of natural photoprotective molecules becomes of great importance. Therefore, in this work we wanted to evaluate the beneficial protective effects of ripe berries of Vaccinium uliginosum (Alaska bog blueberry (BB)) extract $(100 \mu \mathrm{g} / \mathrm{mL})$ for preventing the cutaneous oxidative, inflammatory, and structural damage induced by exposure to $200 \mathrm{~mJ}$ of UVA/UVB radiation. We observed that the topical application of BB extract on human ex vivo skin explants averted the UV-induced cutaneous OxInflammatory phenomenon by quenching the increase in the oxidative and inflammatory marker levels, such as 4-hydroxynonenal (4HNE), heme-oxygenase-1 (HO-1), cyclooxygenase-2 (COX2), and aryl hydrocarbon receptor (AhR); as well as by counteracting the loss of structural proteins (filaggrin and involucrin) induced by UV radiation. Our data propose the use of a topical application of Alaska bog blueberry extract as a natural and valuable approach to ensure photoprotection against UV-induced skin damage and premature aging.
\end{abstract}

Keywords: cosmeceuticals; environmental stressor; oxidation; inflammation; antioxidant; OxInflammation; phytochemicals

\section{Introduction}

The skin is the largest sensory organ in our body, having a surface extension of circa $2 \mathrm{~m}^{2}$. Due to its size and location, the skin is one of the organs most exposed to external stimuli [1], and among these, one of the most aggressive is represented by ultraviolet radiation (UV) [2,3].

The UV radiation region ranges from wavelength of $100 \mathrm{~nm}$ up to $400 \mathrm{~nm}$ and is divided in three different bands: UVA (400-320 nm), UVB (320-290 nm), and UVC (290-200 nm).

The stratospheric layer of ozone is able to entirely absorb the shortest wavelengths of UVC rays and a great percentage of UVB radiation, indeed only 5-10\% of UVB rays can reach Earth's surface. UVA rays, however, are able to almost entirely pass (90-95\%) the stratospheric ozone layer [4,5]. Although UVA radiation is considered a weak energy, it is able to extensively penetrate the skin, reaching the deepest dermal layers. On the 
other hand, UVB rays are mainly absorbed by the epidermis, but due to their high energy radiation, they are more genotoxic than UVA [6].

UV radiation's beneficial effect on human health has been well established. UV is not only able to trigger vitamin D3 synthesis, but it can also improve psoriatic lesions. On the other hand, chronic exposure to UV has been reported as the main risk factor for the development of photoaging and malignant melanoma [7]. Indeed, some evidence possibly correlates the development of $60-70 \%$ of all the cutaneous malignant melanomas with UV exposure [8].

The UV-induced skin damage that ultimately leads to tumorigenesis is caused by the absorption of strongly harmful rays by the cutaneous layers, culminating in oxidative stress. The resulting redox unbalance seems to be caused either via direct DNA damage or via the oxidation of cellular lipid and proteins, due to the generation of reactive oxygen species (ROS) [6].

Although the skin presents a complex antioxidant system [9], problems arise when the exposure to UV becomes chronic, leading to a shift in the balance between oxidants and antioxidants species towards oxidation, with a consequent depletion of the skin's defense system [10]. In fact, chronic exposure to UV has been associated with sunburn, cellular apoptosis, DNA damage, and photo carcinogenesis [11,12].

Considering the cutaneous harmful effects of UV exposure and the strain posed on the skin's defense potential, improving skin protection becomes a major priority.

The use of sunscreen has been the most effective method to reduce the risk prevalence of UV-induced skin cancer [13], by scattering, reflecting, or absorbing UV radiation [14]. Even though, for many years, synthetic and chemical formulations were considered the front runners, recent concerns about their stability and their safety for humans and the marine eco-system [15-17] have skewed attention and interest towards natural photoprotective compounds.

In this context, as the topical application of antioxidant compounds has been proven to be safe and effective for protecting the skin from external stressors $[18,19]$, the need to find new protective molecules offers interesting avenues for future research [20].

In a quest to find effective and promising topical photoprotective compounds, plant species have been researched from folk and traditional medicine, for their antioxidant and anti-inflammatory properties [21]. The physicochemical composition of these herbal remedies is presumably the reason for their beneficial effects, by containing flavonoids, phenolic acids, anthocyanins, and pro-anthocyanidin [22].

Wild Alaska blueberry (BB) (Vaccinium uliginosum, also called 'bog blueberry') is endemic to the wild lands in Alaska and circumpolar regions in the arctic. It is an integral component of the subsistence diet for Alaskan Native communities, and a rich source of polyphenolic compounds that are protective against metabolic disorders, such as diabetes and obesity, as well as other sources of oxidative or inflammatory stress to humans [23,24]. Bog blueberry has been utilized both topically and orally for medicinal use by indigenous people, including the Inuit of Alaska, who also use fermented preparations of these berries [21,25]. As the bog blueberry thrives in the harsh, unprotected extremes of the arctic, with extremely cold winters and up to a 23-h photoperiod during the harvest season, it reacts to environmental stress by producing a copious and diversified array of polyphenolic compounds (including anthocyanins), which aid in habitat survival; a phenomenon known as 'elicitation' [21]. This abundance of health-protective polyphenolics gives the bog blueberry an unusually high antioxidant and anti-inflammatory potency [21,26].

Even though there are many indicators of the possible photoprotective potential of Alaska bog blueberries, the beneficial effects the topical application of BB could have in preventing cutaneous UV-induced damage have never been investigated.

Skin exposure to UV radiation has already been proven to be associated with a vicious cycle of oxidative and inflammatory events (OxInflammation) [27] and to impairment of cutaneous barrier functions [3]. Previously, we demonstrated that topical application of polyphenol-containing natural extracts (wild lowbush blueberry and rosemary) pre- 
vented the pollution-induced loss of cutaneous barrier function and OxInflammatory damage $[18,19]$. With these considerations, in this study we hypothesize that the topical application of anthocyanin-rich BB extract could be beneficial in preventing UV-induced oxidative stress, inflammation, and structural impairment of cutaneous barrier by quenching the direct and indirect sources of oxidative stress.

In this work, we demonstrate that the topical application of Alaska blueberry extract was able to prevent the UV-induced increased expression of oxidative and inflammatory markers and restore the levels of skin-barrier associated proteins previously lost after UV exposure.

\section{Materials and Methods}

\subsection{Plant Material}

Wild Alaskan bog blueberry (BB) (Vaccinium uliginosum L.) were handpicked when fully ripe from the vicinity of Fairbanks, Poker Flat Research Range/Coordinates $65.1256^{\circ} \mathrm{N}$, $147.4919^{\circ} \mathrm{W}, \mathrm{AK}, \mathrm{USA}$ in summer 2018 . Berries were immediately stored at $-80^{\circ} \mathrm{C}$ and shipped to Kannapolis, NC, USA on dry ice. Samples were stored at $-80^{\circ} \mathrm{C}$ until used for extraction.

\subsection{Extraction and Polyphenol Enrichment}

Frozen bog blueberries ( $25 \mathrm{~g}$ ) were thawed down to room temperature before homogenization in $50 \mathrm{~mL} \mathrm{90 \%} \mathrm{acidified} \mathrm{methanol} \mathrm{(} 0.5 \%$ acetic acid) for $1 \mathrm{~min}$. The mixture was centrifuged (Sorvall RC-6 plus, Asheville, NC, USA) for $10 \mathrm{~min}$ at $4000 \mathrm{rpm}$ and supernatant was collected. Extraction was repeated two more times, and the collected supernatants were evaporated under vacuum at $40^{\circ} \mathrm{C}$ in a rotary evaporator and freeze-dried to produce the crude bog blueberry extract $(2.9 \mathrm{~g})$. The crude extract was dissolved in DI water $(6 \mathrm{~mL}$ ) and passed through 6 preconditioned C18 SPE tubes (Strata X $33 \mu \mathrm{m} 100 \mathrm{mg}$ tubes, Phenomenex, CA, USA). The tubes were washed with acidified water ( $0.5 \%$ acetic acid) to get rid of soluble sugars and organic acids before elution of the polyphenols with 100\% methanol. The methanol was evaporated $\left(40^{\circ} \mathrm{C}\right)$ and the residual material was freeze-dried to afford the $0.33 \mathrm{~g}$ polyphenol-rich extract of bog blueberry. The polyphenol-enriched extract was used in all skin experiments.

The identification of compounds was based on HPLC against the available standard and LC-MS/MS [28]. Peaks were quantified based on peak area measurement against a standard curve constructed with the cyanidin-3-O-glucoside reference standard, and results were expressed as $\mu \mathrm{g} / \mathrm{mg}$ cyanidin glucoside equivalent.

\subsection{HPLC Conditions}

Anthocyanin (ANC) profiles were analyzed by HPLC-DAD, using an Agilent 1200 series HPLC (Agilent Technologies, Santa Clara, CA, USA) equipped with a photodiode array detector (DAD) set at $520 \mathrm{~nm}$. The chromatographic separation was performed on an RP Supelcosil-LC-18 column, $250 \mathrm{~mm} \times 4.6 \mathrm{~mm} \times 5 \mathrm{G} \mu \mathrm{m}$ (Supelco, Bellefonte, PA, USA), according to our previously described method [29].

\subsection{Ex Vivo Human Skin Explants Preparation}

Human skin biopsies were obtained from Hunstad/Kortesis/Bharti Cosmetic Surgery clinic, where elective abdominoplasties were performed on three Caucasian healthy donors, as approved by the IBC at NC State University (Raleigh, NC, USA).

A total of 36 punch biopsies, of $12 \mathrm{~mm}$ diameter each, were taken from each donor's abdominal skin and the subcutaneous fat was removed right away, with the help of sterile scissors and scalpel, leaving only the dermal and epidermal layers.

Following this, the collected biopsies were rinsed with phosphate-buffered saline (PBS, Gibco, NY, USA) and moved into 6-well plates containing $2 \mathrm{~mL}$ of complete Dulbecco's modified Eagle medium (DMEM) with the addition of $10 \%$ fetal bovine serum (FBS) and 
$1 \%$ of antibiotics and antimycotics (100 U/mL penicillin and $100 \mu \mathrm{g} / \mathrm{mL}$, Gibco, NY, USA), then incubated at $37^{\circ} \mathrm{C}$ in $5 \% \mathrm{CO}_{2}$ for overnight recovery.

The experiment was performed at least in triplicates for each condition and for each donor.

\subsection{Alaska Blueberry (BB) Extract Preparation and Ex Vivo Human Skin Explants Pre-Treatment}

The frozen BB extract powder was solubilized in dimethylsulfoxyde (DMSO) (20688, $99.5 \%$, Thermo Fisher Scientific) to obtain a stock solution of $100 \mathrm{mg} / \mathrm{mL}$, which was then aliquoted and stored at $-80^{\circ} \mathrm{C}$. On the day of each pre-treatment, a new freshly made BB formulation was prepared by diluting the stock solution in complete media to reach a final concentration of $100 \mu \mathrm{g} / \mathrm{mL}$ (containing a final concentration of DMSO of $0.1 \%$ ).

The morning after overnight recovery, media in the wells was replaced with a fresh complete one and each biopsy was topically applied with $30 \mu \mathrm{L}$ of Alaska blueberry extract $(100 \mu \mathrm{g} / \mathrm{mL})$, which was evenly spread with a glass rod. Following this, plates were incubated in humidified 5\% $\mathrm{CO}_{2} / 95 \%$ air atmosphere for $24 \mathrm{~h}$.

\subsection{Ex Vivo Human Skin Explants Ultraviolet Light (UV) Exposure}

After $24 \mathrm{~h}$ of BB pre-treatment, the human skin biopsies were exposed to 200 milli Joule (mJ) UVA/UVB light (circa 20 s) generated by Sol1A Class ABB Solar Simulator, equipped with xenon lamp (Newport Oriel Sol1A, 1600 W, UVC \&AM0 filters, Irvine, CA, USA). The UVA/UVB ratio was 21:1, to closely match the solar spectrum at the condition of the sun at Zenith angle of 0 . To ensure correct levels of UV exposure, the doses of radiation were monitor using a radiometer, ILT2400 Hang-Held Light Meter/Optometer (International Light technologies, Inc., Peabody, MA, USA). The dose 200 mJ UVA/UVB was the standard dose of exposure chosen for sun-sensitive individuals and corresponds to circa 10 minimal erythemal dose (MED, with $1 \mathrm{MED}=20 \mathrm{~mJ} / \mathrm{cm}^{2}$ ); which in real life equates to circa $2 \mathrm{~h}$ at solar apex [30].

Samples were collected upon UV exposure (T0), 6 h (T6), or after $24 \mathrm{~h}$ (T24).

\subsection{Immunofluorescence}

In preparation for immunohistochemical analysis, skin explants were fixed in normal buffered formalin (NBF) $10 \%$ for $48 \mathrm{~h}$ at $4{ }^{\circ} \mathrm{C}$ and then dehydrated using increasing alcohol gradients, followed by immersion in xylene and paraffin embedding.

Next, $4 \mu \mathrm{m}$ sections of paraffin-embedded skin explants were deparaffined by heat $\left(65{ }^{\circ} \mathrm{C}\right.$ for $\left.30 \mathrm{~min}\right)$ and xylene, then rehydrated in decreasing alcohol gradients. Following this, antigen retrieval was achieved via heat-based epitope retrieval with sodium citrate buffer at $\mathrm{pH}$ 6.0 (Thermo Fisher Scientific, Waltham, MA, USA) at a sub-boiling temperature in a water bath set at $95^{\circ} \mathrm{C}$ for $8 \mathrm{~min}$.

After cooling down, sections were washed twice with phosphate buffered saline (PBS) $1 \times$ and blocked with 5\% bovine serum albumin (BSA) in PBS for $1 \mathrm{~h}$. Following this, sections were incubated overnight at $4{ }^{\circ} \mathrm{C}$ with primary antibodies for $4 \mathrm{HNE}$ (dil. 1:400; AB5605, Millipore), AhR (NB 100-128, Novus, 1:150), COX2 (NB 100-868, Novus, $10 \mu \mathrm{g} / \mathrm{mL}$ ), and prepared in $2 \%$ BSA/PBS.

The following day, sections were washed $3 \times 5$ min with PBS 1X, then incubated for $45 \mathrm{~min}$ at room temperature with s fluorochrome-conjugated secondary antibodies (dil 1:500) (A11008 Alexa Fluor 488, A11055 Alexa Fluor 488) in 2\% BSA/PBS.

Sections were washed $3 \times 5$ min with PBS $1 X$ and then incubated with DAPI (1874814, Invitrogen) (dil 1:20,000) in PBS for $90 \mathrm{~s}$ in the dark to stain nuclei. Next, sections were washed $3 \times 5$ min with PBS 1 X, followed by 1 wash of 5 min with DDI water. Finally, sections were mounted using aqueous PermaFluor mounting medium (TA-006-FM, Thermo Fisher Scientific, Waltham, MA, USA) and imaged on a Zeiss LSM10 microscope. Fluorescence intensity was quantified using ImageJ. 


\subsection{Hematoxylin and Eosin (HEE) Staining}

For H\&E observation, freshly cut $4 \mu \mathrm{m}$ thick sections were deparaffinized in xylene and then rehydrated in decreasing alcohol gradients. Next, skin sections were stained for $10 \mathrm{~min}$ at room temperature, with Mayer's hematoxylin solution (26043-06, Electron Microscopy Sciences, Hatfield, PA, USA). Following this, sections were rinsed with lukewarm tap water for $15 \mathrm{~min}$ and then stained with aqueous Eosin Y solution (786-1072, G-Biosciences St. Louis, MO, USA) for $3 \mathrm{~min}$. Upon staining, the sections were dehydrated in increasing alcohol solutions, terminating with xylene. Subsequently, the sections were mounted onto glass slides using a toluene-based solution (SP15-100, Fisher Chemical, Chicago, IL, USA) and images were taken with (EVOS FL Auto, Life Technologies Carlsbad, CA, USA). Scale bar $100 \mu \mathrm{m}$.

\subsection{Western Blot Assay}

First, circa $60 \mathrm{mg}$ of ex vivo human skin explants were homogenized in $500 \mu \mathrm{L}$ of cold lysis buffer (containing Hepes, KOH 20 mM (pH 7.5), KCl 150 mM, NP-40 1\%, 1\% protease inhibitor cocktails (Sigma-Aldrich, Burlington, MA, USA), and PMSF 0.1mM). Homogenization was performed with tissue homogenizer (Precellys 24 homogenizer, 10 cycles $6500 \mathrm{rpm} 3 \times 30 \mathrm{~s}$, at $4{ }^{\circ} \mathrm{C}$ ).

Following this, $10 \%$ polyacrylamide SDS gel were loaded with $15 \mu \mathrm{g}$ of denatured proteins, separated by molecular size. The gel was then electroblotted at $80 \mathrm{~V}$ for $45 \mathrm{~min}$ onto nitrocellulose membranes and blocked for $5 \mathrm{~min}$ at room temperature with EveryBlot Blocking Buffer (12010020, Bio-Rad, Hercules, CA, USA). Nitrocellulose membranes were then incubated overnight at $4{ }^{\circ} \mathrm{C}$ with primary antibodies: HO-1 (dil 1:1,000, NOVUS NBP1-31341), Filaggrin (dil 1:1,000, Santa Cruz sc-66192), and Involucrin (dil 1:500 Santa Cruz sc-21748), prepared in EveryBlot Blocking Buffer.

The next morning, membranes were washed $5 \times 5$ min with TBS-T at room temperature under mild shaking and incubated for $1 \mathrm{~h}$ at room temperature with secondary antibody conjugated with horseradish peroxidase (dil 1:10,000), prepared in EveryBlot Blocking Buffer.

Chemiluminescence signal was detected and Beta-Actin (dil 1: 100,000, A3854, SigmaAldrich, Burlington, MA, USA) was used as loading control.

Finally, bands were digitalized and densitometry analysis was performed using ImageJ Software.

\subsection{Statistical Analyses}

To evaluate differences between groups, analysis of variance (ANOVA) followed by Tukey's multiple comparisons was performed with GraphPad Prism 6 software (GraphPad Software Inc., https: / / www.graphpad.com/, accessed on 15 September 2021), considering timepoints separately.

All data were expressed as means \pm standard deviations and statistical differences between means were determined using a $p \leq 0.05$ significance level.

\section{Results}

\subsection{Polyphenolic Composition of Wild Alaska Bog Blueberry Extract}

The first step was the determination and quantification of the anthocyanin (ANC) content in wild Alaskan bog blueberry (BB) extracts. Crude extract contained $17.8 \mathrm{mg} / \mathrm{g}$ total anthocyanins, measured as cyanidin-3-glucoside equivalent. The SPE polyphenol enrichment procedure resulted in $308.6 \mathrm{mg} / \mathrm{g}$ total anthocyanins in the polyphenol-enriched extract ( $>15$ fold higher than crude extract). As shown in Figure 1 (Figure 1) the HPLC chromatogram shows that glucosides of malvidin (peak 13) and delphinidin (peak 2) represent $>40 \%$ of total ANC, followed by petunidin glucoside (peak 8), constituting around $12 \%$ of the total ANC content. 


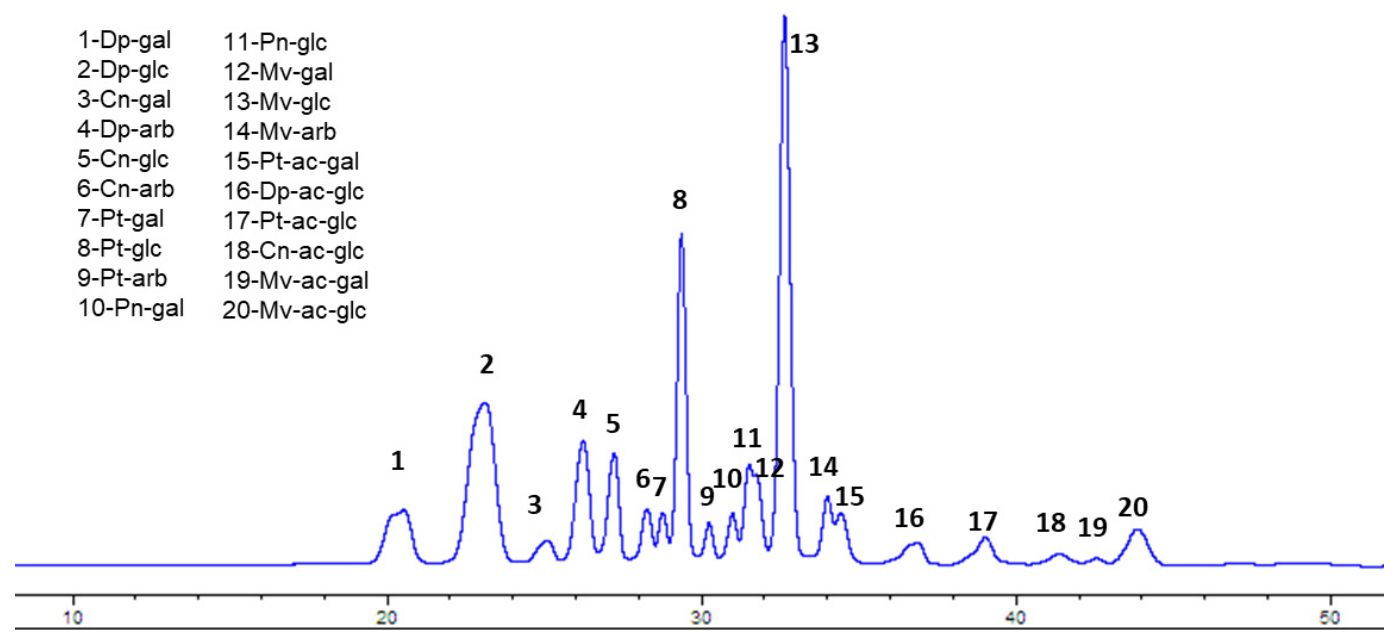

Figure 1. HPLC profile of Alaskan bog blueberry with identification of individual peaks. $\mathrm{Dp}=$ delphinidin, $\mathrm{Cn}=\mathrm{cyanidin}$, $\mathrm{Pt}=$ petunidin, $\mathrm{Pn}=$ peonidin, $\mathrm{Mv}=$ malvidin, $\mathrm{ac}=$ acetoyl, $\mathrm{gal}=$ galactose, $\mathrm{glc}=$ glucose, arb $=$ arabinose .

\subsection{Effect of UV Exposure on Skin Structure and Morphology}

After the evaluation of the polyphenolic qualitative and quantitative composition of BB extract, we wanted to investigate the effect of UV exposure and BB extract on the morphology/structure of the cutaneous tissues. As shown in Figure 2, the extract did not produce any morphological nor structural changes in tissues, with or without UV exposure, at all of the timepoints considered.

Air
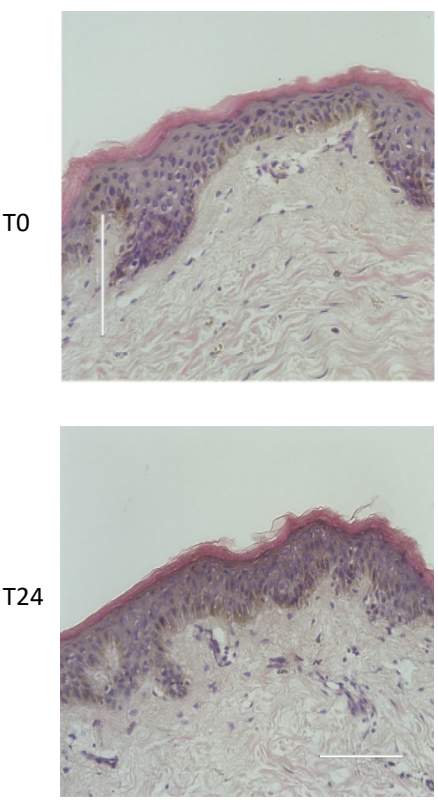

BB
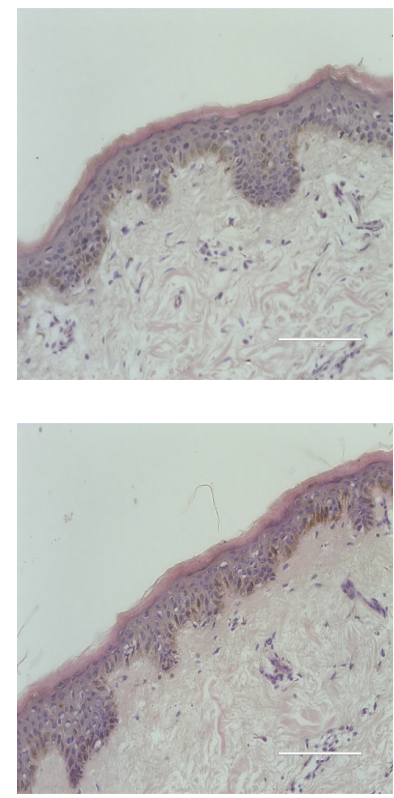

UV
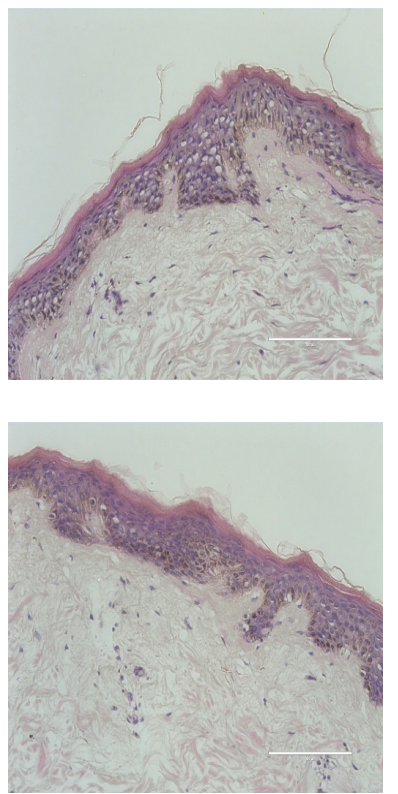

UV BB
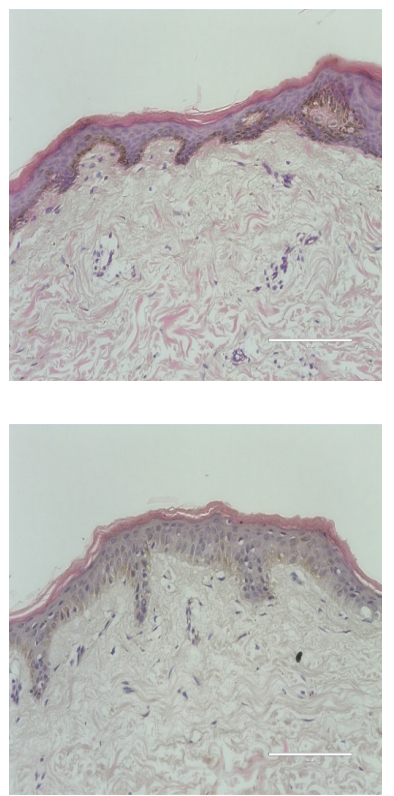

Figure 2. Tissue structure and morphology upon BB pre-treatment and UV exposure. H\&E staining of ex vivo human skin explants, untreated or pre-treated with Alaskan blueberry extract (BB) and then exposed to UV light (200 mJ of UVA/UVB). Scale bar $100 \mu \mathrm{m}$.

\subsection{Effect of UV Exposure on Cutaneous Oxinflammatory Responses}

Exposure to UV radiation can generate ROS that subsequently lead to the oxidation of biological molecules, such as lipids, proteins, and DNA [4]. An important marker of lipid peroxidation is 4-hydroxy-nonenal (4HNE) [31]. As shown in Figure 3a,b, after $6 \mathrm{~h}$ from UV exposure (T6) we detected increased $4 \mathrm{HNE}$ protein levels in skin exposed to UV 
light compared to the air control (Figure 3a,b). We also observed that pre-treatment with $\mathrm{BB}$ counteracted the UV-induced $4 \mathrm{HNE}$ levels. Interestingly, after $24 \mathrm{~h}$ from the oxidant exposure, $4 \mathrm{HNE}$ levels were back to the baseline, suggesting that lipid peroxidation is one of the early steps promoted by UV radiation in the cascade of oxidative damage (Figure 3a,b).

To further corroborate the induction of redox damage by UV exposure, we evaluated the protein levels of heme oxygenase-1 (HO-1), an important antioxidant enzyme that is known to be activated in the presence of oxidative challenges, including UV radiation [32].

As shown in Figure 3c,d, after $24 \mathrm{~h}$ from UV exposure, skin tissues exposed to UV exhibited a significant induction of HO-1 levels compared to the control and, most importantly, this increase was prevented by BB topical application (Figure 3c,d).
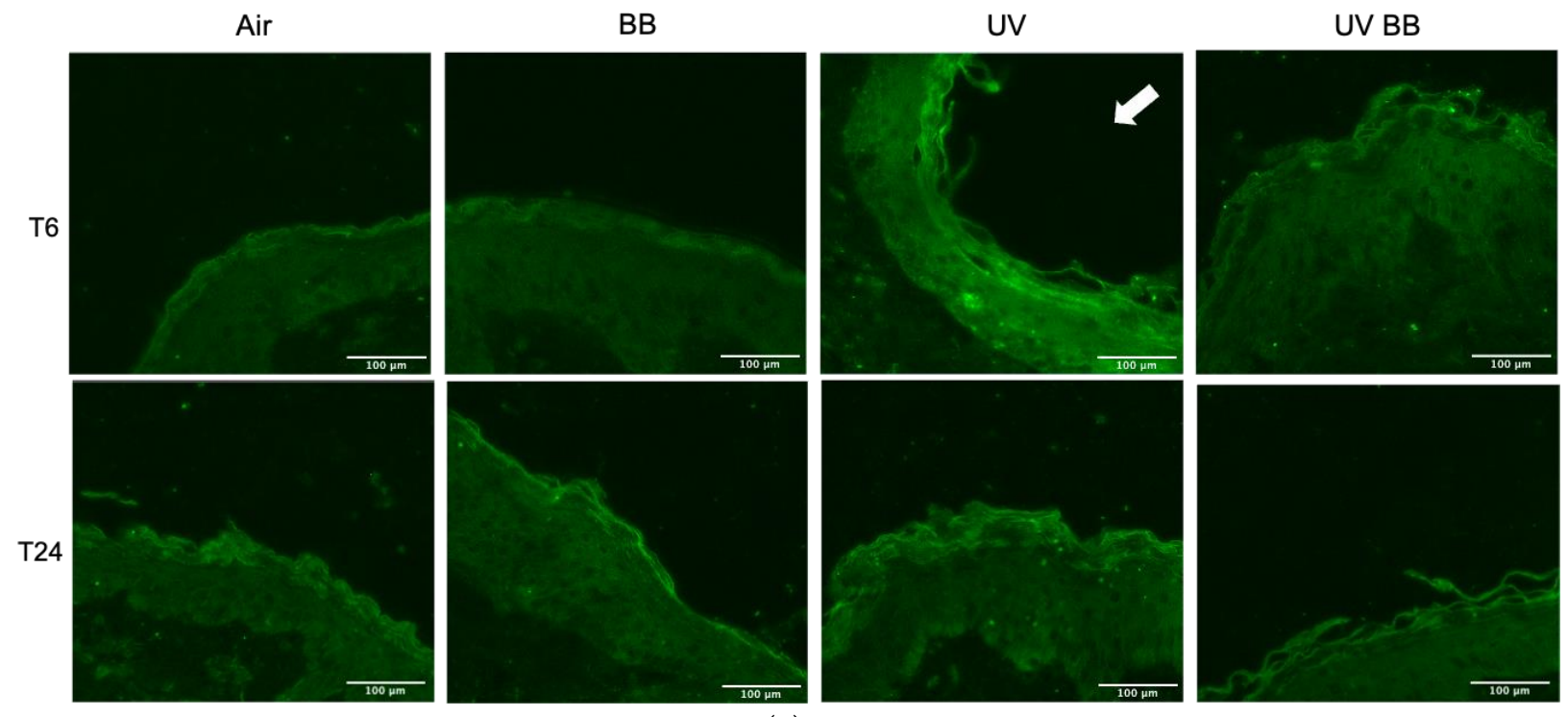

(a)

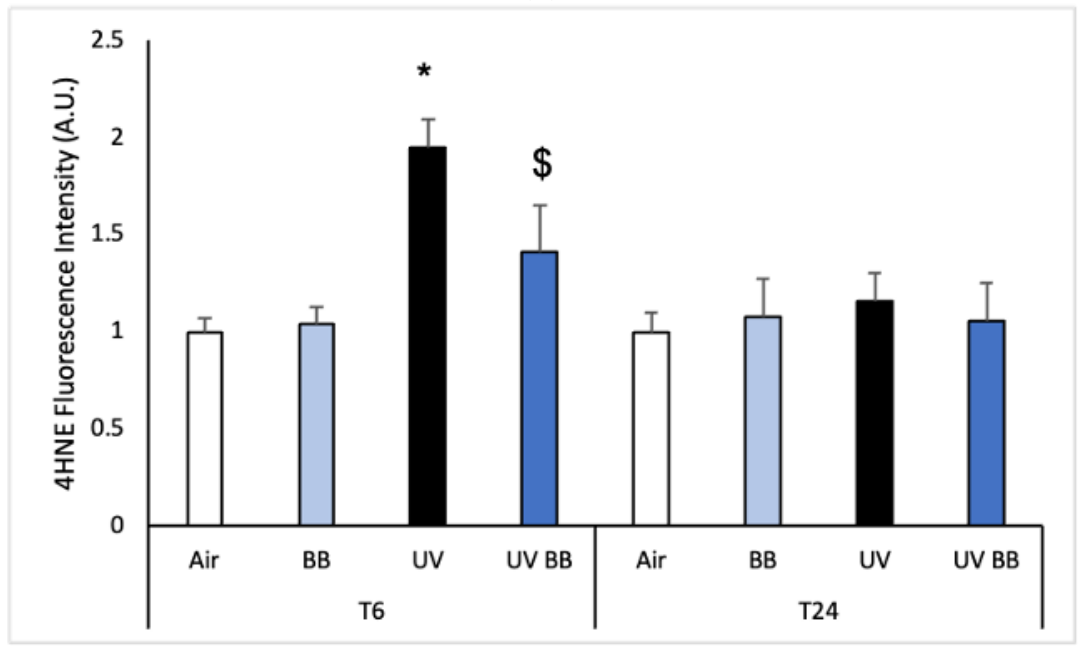

(b)

Figure 3. Cont. 


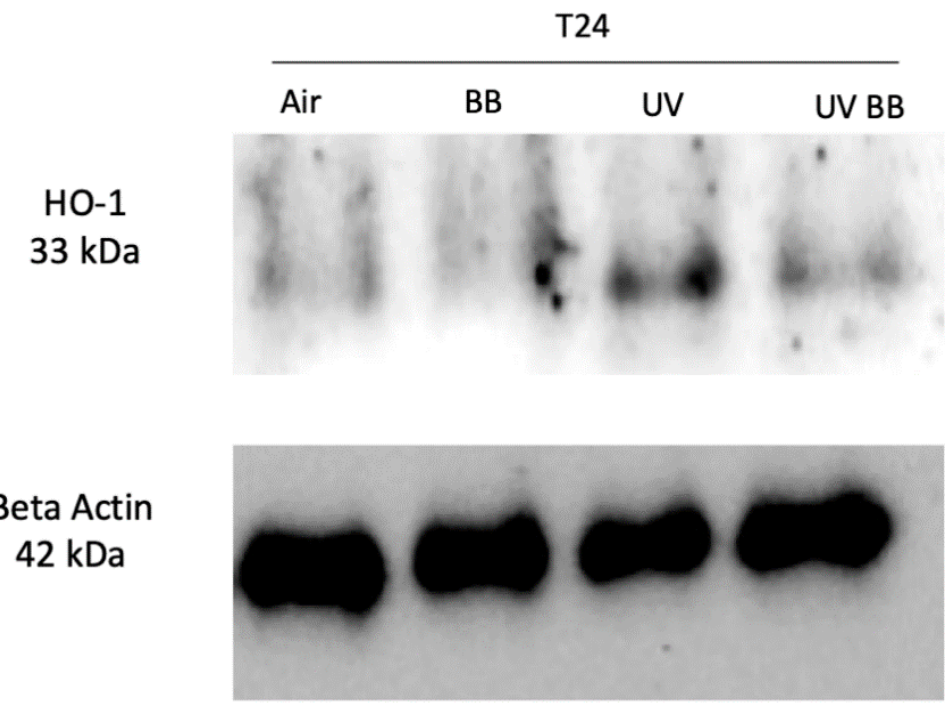

(c)

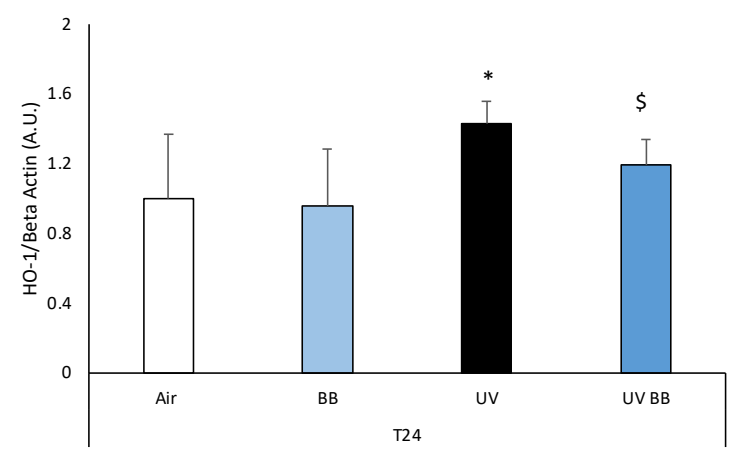

(d)

Figure 3. Skin exposure to UV induces peroxidative damage (4HNE, HO-1), however, pre-treatment with BB extract prevents this oxidative damage. Ex vivo human skin biopsies were untreated or pre-treated with $\mathrm{BB}$ and then exposed to $200 \mathrm{~mJ}$ of UVA/UVB, following $4 \mathrm{HNE}$, and HO-1 protein levels were evaluated. (a) Green fluorescence staining represents $4 \mathrm{HNE}-$ protein adduct levels at the original magnification $40 \times$. (b) Semi-quantification of $4 \mathrm{HNE}$ green fluorescence intensities performed with ImageJ are depicted in the histogram panel. (c) HO-1 protein levels measured via Western blot assay at $24 \mathrm{~h}$ (T24) upon UV exposure. (d) Relative quantification of HO-1 protein levels measured by ImageJ. Data are expressed as arbitrary units (average of three independent experiments), ${ }^{*} p<0.05$ Air vs. UV; $\$ p<0.05$ UV vs. UV BB by ANOVA. Scale bar $100 \mu \mathrm{m}$.

\subsection{Effect of UV Exposure on Cutaneous Inflammatory Status}

As a result of oxidative stress, redox sensitive transcription factors (NFkB, AP-1, and $\mathrm{AhR}$ ) can be activated and can induce the transcription of inflammatory genes, such cyclooxygenase-2 (COX2) [33].

To further evaluate the effect of UV exposure on skin redox homeostasis and the protective properties of BB extract, we measured the levels of AhR. Right after UV exposure (T0) there were no visible effects; whereas, after $24 \mathrm{~h}$ from UV exposure, as shown in Figure 4a, there was an increase in AhR levels in the biopsies exposed to UV, and also in this case, pre-treatment with BB abolished UV-induced AhR expression (Figure 4a,b). 


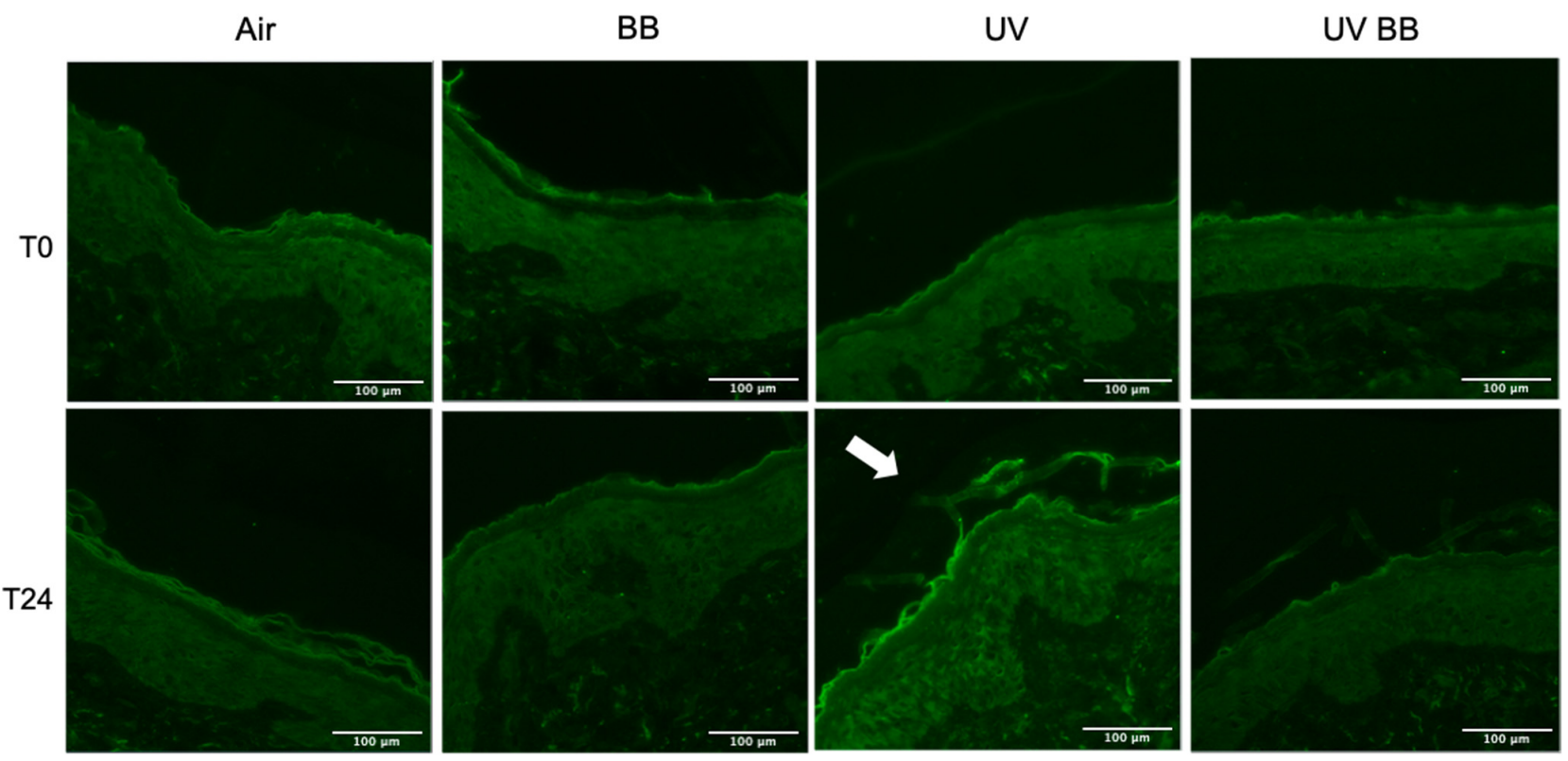

(a)

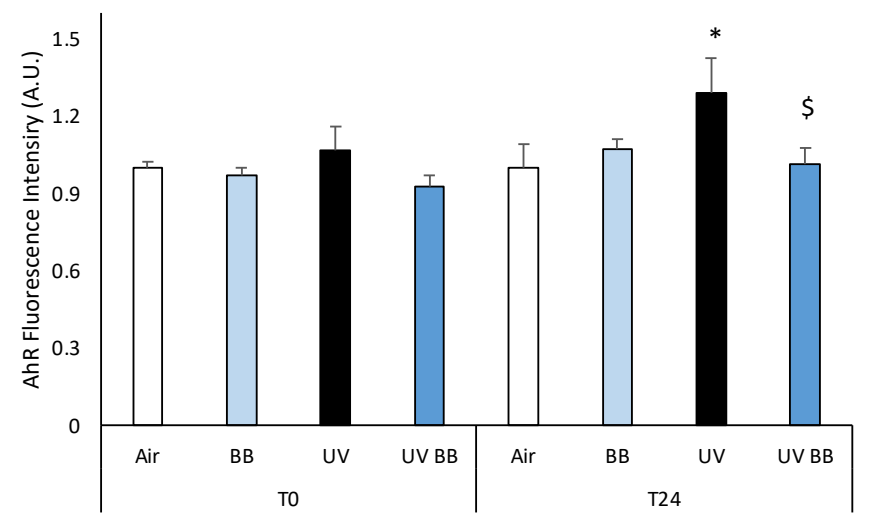

(b)

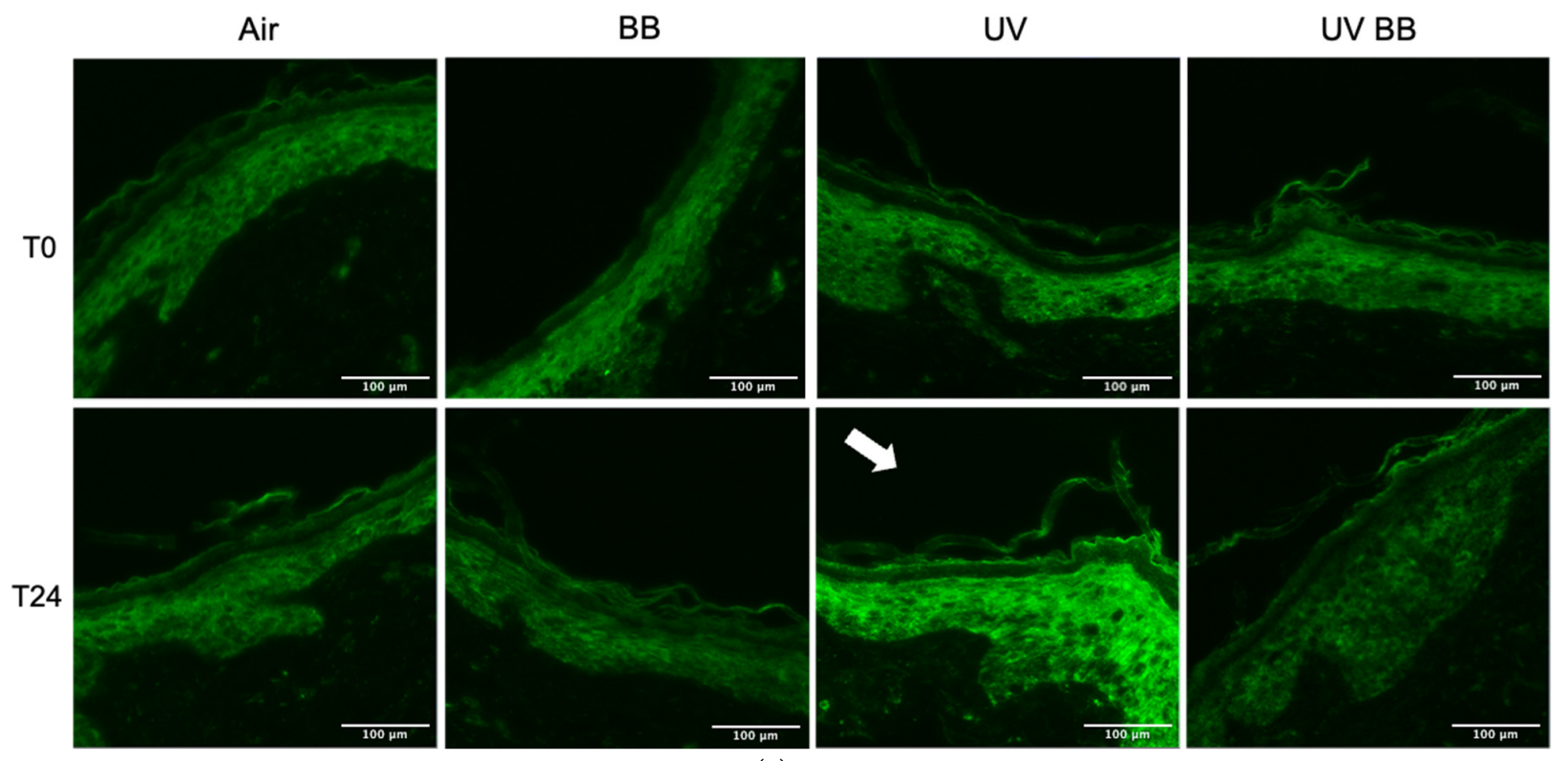

(c)

Figure 4. Cont. 


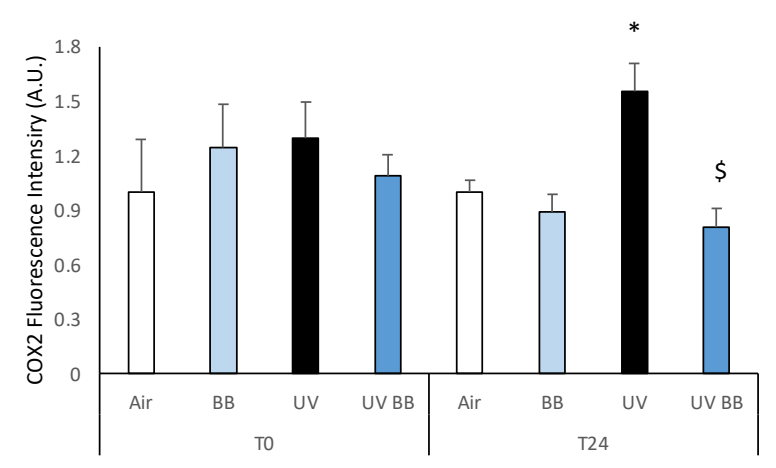

(d)

Figure 4. Skin exposure to UV induces inflammatory damage, but pre-treatment with BB extract prevents the induction of pro-inflammatory markers. Ex vivo human skin biopsies were untreated or pre-treated with BB and then exposed to $200 \mathrm{~mJ}$ of UVA/UVB, then, AhR and COX2 protein levels were evaluated via immunofluorescence. (a) Green fluorescence staining represents AhR protein levels at the original magnification $40 \times$. (b) Semi-quantification of AhR green fluorescence intensities produced with ImageJ are depicted in the histogram panel. (c) Green fluorescence staining represents COX2 protein levels at the original magnification $40 \times$. (d) Semi-quantification of COX2 green fluorescence intensities produced with ImageJ are depicted in the histogram panel. Data are expressed as arbitrary units (average of three independent experiments), ${ }^{*} p<0.05$ Air vs. UV; $\$ p<0.05$ UV vs. UV BB by ANOVA. Scale bar $100 \mu \mathrm{m}$.

As aforementioned, the expression of pro-inflammatory proteins can be strongly induced by redox imbalance; thus, we evaluated the levels of COX2, an important inflammatory marker. Figure $4 \mathrm{c}, \mathrm{d}$ show the ability of UV radiation to induce increased COX2 levels only after $24 \mathrm{~h}$ (T24), while, the pre-treatment with BB extract was able to prevent COX2 upregulation.

\subsection{Effect of UV Exposure on Skin-Barrier Associated Proteins}

Inflammatory skin conditions have, as a common denominator, impaired skin barrier functions; therefore, we decided to evaluate the expression of proteins important in this role.

First, we evaluated the effects of UV exposure on filaggrin, a protein involved in the maintenance of the stratum corneum barrier properties [34].

We observed that ex vivo human skin exposed to $200 \mathrm{~mJ}$ of $\mathrm{UV}$ radiation induced a significant downregulation of filaggrin levels after $24 \mathrm{~h}$ from UV exposure, compared to control. Furthermore, topical application with BB extract counteracted the loss of filaggrin induced by UV (Figure 5a,b).

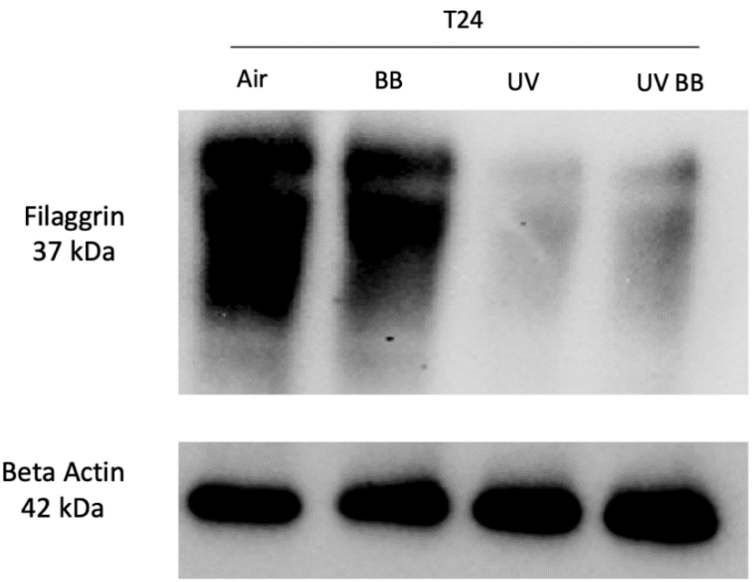

(a)

Figure 5. Cont. 


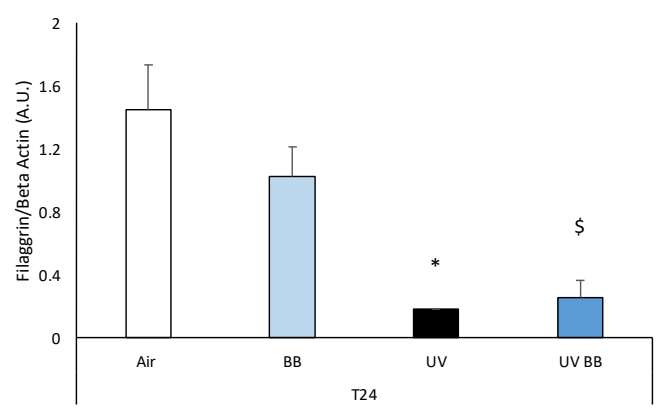

(b)

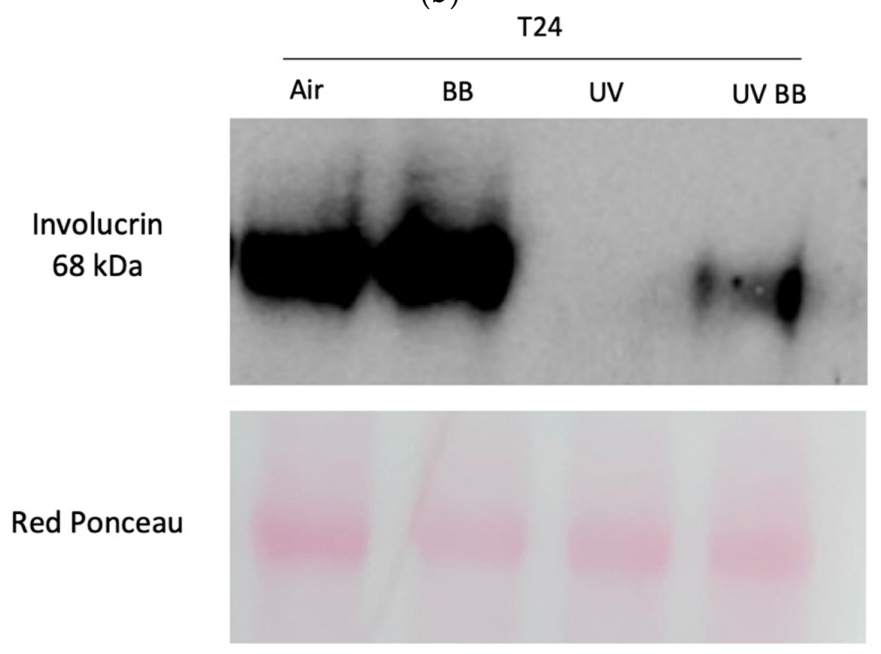

(c)

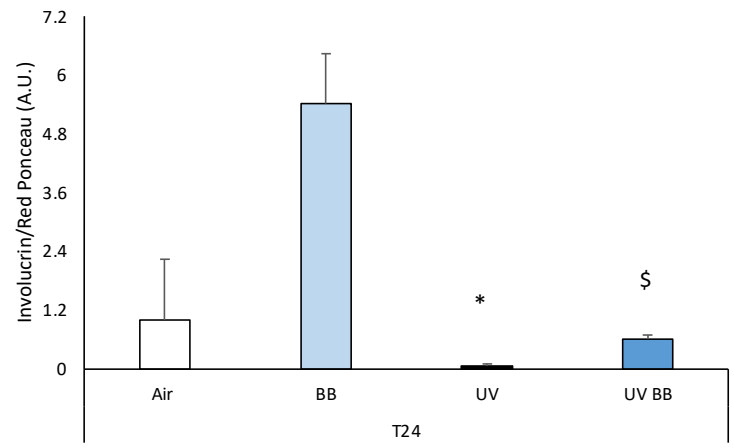

(d)

Figure 5. Skin exposure to UV impairs skin barrier functions (filaggrin, involucrin), which were normalized by the pre-treatment with BB extract. Ex vivo human skin biopsies were untreated or pre-treated with $\mathrm{BB}$ and then exposed to $200 \mathrm{~mJ}$ of UVA/UVB, then, filaggrin and involucrin protein levels were evaluated. (a) Filaggrin protein levels measured via Western blot assay at $24 \mathrm{~h}$ (T24) upon UV exposure. (b) Relative quantification of filaggrin protein levels measured by ImageJ. (c) Involucrin protein levels measured via Western blot assay at $24 \mathrm{~h}$ (T24) upon UV exposure. (d) Relative quantification of involucrin protein levels measured by ImageJ. Data are expressed as arbitrary units (average of three independent experiments), ${ }^{*} p<0.05$ Air vs. UV; $\$ p<0.05$ UV vs. UV BB by ANOVA.

Another important protein for skin structure and barrier properties is involucrin, due to its role in the formation of the stratum corneum cornified envelope [35].

Additionally, in this case, we observed a decrease of involucrin protein levels in skin exposed to UV at T24, and BB pre-treatment was able to avert this effect (Figure 5c,d). 


\section{Discussion}

Due to its location and size, skin represents not only a target for environmental stressors but also the first line of protection against them [1], while UV radiation represents the most aggressive cutaneous stressor [2,3].

Exposure to UV light has been deeply investigated in recent decades, and its harmful effects on skin tissue have been uncovered [12,36].

It is well known that solar radiation induces skin damage via the photochemical generation of reactive nitrogen (RNS) and oxygen species (ROS), such as nitric oxide (NO), superoxide anion $\left(\mathrm{O}_{2}\right)$, hydrogen peroxide $\left(\mathrm{H}_{2} \mathrm{O}_{2}\right)$, and hydroxyl radical $(\mathrm{OH} \cdot)$. These radical species can interact with different cellular biomolecules, such as DNA, protein, and lipids, inducing multiple oxidative cascades that can then cause extensive cellular damage, with loss of structure and functionality of the tissue [37].

Multiple works have identified UV light as the primary risk factor in the development of extrinsic photoaging (characterized by coarse wrinkles, pigmented spots (lentigines) and uneven skin tone [38]) and skin cancer [7]. Therefore, prevention from UV exposure is important, not only at a cosmetic level, but also to avoid the triggering/exacerbation of severe skin pathologies.

In this context, the research of molecules able to quench this UV-induced cutaneous damage becomes increasingly important.

Recently there has been a turn of events in the field of sunscreen formulations, where we have seen an increasing demand for natural extracts, in replacement of synthetic and chemical sunscreens [39-42]. This started after many reports brought to light the instability and inability of organic sunscreens to completely dissipate the energy absorbed by UV light, leading to the generation of free radical species that can cause further skin damage $[15,16]$. Furthermore, in the last two years, chemical sunscreens containing synthetic compounds such as oxybenzone and octinoxate have been banned in some countries [43], because of the potential harm induced to coral reefs and other marine ecosystems [17].

Natural compounds have been demonstrated to be safe and capable of protecting the skin from free radicals and photoaging $[41,42,44,45]$ thanks to their polyphenolic composition, which is an index of the environmental stress the plant has gone through during the growth phase. Specifically, it has been demonstrated in humans that the topical application of natural antioxidants before exposure to UVA radiation reduces the photodermatoses induced by UVA light and increases the minimal dose to induce pigment darkening $[44,46]$.

We wanted to confirm in our skin model the well-known ability of UV light to induce oxidative damage, thus we evaluated the levels of $4 \mathrm{HNE}$-protein adducts and found them to be elevated upon UV exposure and demonstrated that pre-treatment with Alaska blueberry extract was able to prevent its formation.

It is common knowledge that oxidative stress is associated with consequent inflammatory cascades via the activation of redox sensitive transcription factors such as the nuclear factor kappa-light-chain-enhancer of activated B cells (NF-kB) pathway [33]. This vicious cycle, where oxidative species caused by exogenous stimuli trigger and are induced by pro-inflammatory events, is known as OxInflammation [27]. As expected, we did not see any OxInflammatory response or structural variation at T0 (right after UV exposure), due to the time required for signaling pathways to be triggered. We confirmed UV's ability to induce inflammation via the increase at $24 \mathrm{~h}$ of the pro-inflammatory marker COX2, which was prevented by the topical application with BB extract at $24 \mathrm{~h}$ from UV exposure. The induction of cutaneous COX2 via NFkB has been also demonstrated by other pollutants, such as ozone [47], and, therefore, it is possible that BB would also be able to prevent ozone damage to the skin.

We speculate that the ability of BB to prevent UV-induced oxidative damage is via the modulation of the cellular defense pathway nuclear factor erythroid 2-related factor 2 (Nrf2). Although we did not directly measure the levels of Nrf2, we evaluated the protein expression of one of the products regulated by Nrf2: the antioxidant enzyme HO-1. Indeed, 
we demonstrated that topical application of BB extract prevents the UV-induced increase of HO-1 levels, a very well-known outcome of UV exposure [32,48]. It has been demonstrated that after UV exposure, skin tissue activates the Nrf2 pathway and increases the transcription of $\mathrm{HO}-1$; therefore, the ability of $\mathrm{BB}$ to prevent $\mathrm{HO}-1$ induction can be read as a lack of Nrf2 activation.

Another mechanism that the skin has to sense outdoor stressors (xenobiotics) is via expression of the aryl hydrocarbon receptor (AhR), a ligand-activated transcription factor. We showed that UV exposure activates AhR after $24 \mathrm{~h}$. Moreover, in this case, other pollutants such as ozone, cigarette smoke, and particulate matter (PM) have been shown to activate AhR, possibly as a response to the formation of ROS [3]. Indeed, the increased levels of superoxide anion or $\mathrm{H}_{2} \mathrm{O}_{2}$ produced by NADPH oxidase (NOX) that can be activated by UV [49] can regulate the AhR signaling pathway, connecting AhR activation to oxidative stress responses [50].

Pre-treatment with Alaska blueberry extract reduced the activation of AhR upon UV exposure, possibly due to the reduction of UV-induced peroxides.

UV-generated ROS can induce OxInflammatory damage in the dermal layers, as well as in the epidermis, where they can impair cutaneous barrier functions by affecting the protein expression and composition [3]. Indeed, we have shown that the levels of filaggrin and involucrin, respectively, involved in the maintenance of stratum corneum properties and in the formation of keratinocytes cornified cell envelope, were clearly affected by UV exposure.

The lowering of filaggrin levels has been observed in multiple chronic inflammatory skin conditions, such as ichthyosis vulgaris and atopic dermatitis [51-53]. Of note, recent evidence suggested that the impairment of cutaneous barrier functions can favor the entry of external pathogens and environmental pollutants; therefore, possibly worsening preexisting skin conditions $[54,55]$. In light of these considerations, we wanted to evaluate the topical application of $\mathrm{BB}$ extract as a possible way to prevent the onset, or reduce the severity, of cutaneous inflammation, and, in fact, BB topical treatment significantly improved the levels of filaggrin and involucrin, previously affected by UV exposure.

It is possible that the beneficial effect of Alaska blueberries resides in their ability to modulate the Nrf2 pathway, which not only induces a strong defensive cellular response [56], but also attenuates the activation of the pro-inflammatory NF-kB pathway [57]; thus, BB extract could possibly counteract oxidative stress in two ways.

Even though this is a preliminary study performed on ex vivo human skin biopsies that present donor variability and lack circulation and innervation, these data are promising, because they uncover the beneficial effects of the topical application of Alaska blueberry extract in counteracting cutaneous OxInflammatory damage and possibly premature skin aging. Of course, before extrapolating the data to real life, it should be mentioned that the approach used in this study has some limitations, related to the skin model (as described above) and to the BB extract; as it needs a proper cosmetic formulation, tested pre-clinically and eventually in a study. Further work is needed to evaluate the chemical characteristics and properties of Alaskan BB extract as a possible new and natural technology to prevent pollution induced skin damage.

Author Contributions: Conceptualization, E.P., M.A.L. and G.V.; Formal analysis, E.P., Z.H., A.P., M.G., J.-P.T. and G.V.; Funding acquisition, G.V. and M.A.L.; Investigation, E.P., Z.H., A.P., M.G., and G.V.; Methodology, E.P., Z.H., A.P., M.G. and J.-P.T.; Resources, G.V.; Supervision, G.V. and M.A.L.; Validation, G.V. and M.A.L.; Visualization, E.P. and A.P.; Writing-original draft, E.P., M.G., M.A.L. and G.V.; Writing-review \& editing, E.P. and G.V. All authors have read and agreed to the published version of the manuscript.

Funding: This research was partially funded by Amway.

Institutional Review Board Statement: Not applicable, as skin biopsies were purchased as waste material from a local hospital.

Informed Consent Statement: Not applicable. 
Data Availability Statement: Data is contained within the article.

Acknowledgments: The authors are thankful to Amway for partial support.

Conflicts of Interest: The authors declare no conflict of interest.

\section{References}

1. Zimmermann, K.A. Skin: The Human Body's Largest Organ. Live Sci. 2018. Available online: https://www.livescience.com/2711 5-skin-facts-diseases-conditions.html (accessed on 1 October 2021).

2. Ferrara, F.; Pambianchi, E.; Woodby, B.; Messano, N.; Therrien, J.P.; Pecorelli, A.; Canella, R.; Valacchi, G. Evaluating the effect of ozone in UV induced skin damage. Toxicol. Lett. 2021, 338, 40-50. [CrossRef]

3. Ferrara, F.; Woodby, B.; Pecorelli, A.; Schiavone, M.L.; Pambianchi, E.; Messano, N.; Therrien, J.P.; Choudhary, H.; Valacchi, G. Additive effect of combined pollutants to UV induced skin OxInflammation damage. Evaluating the protective topical application of a cosmeceutical mixture formulation. Redox Biol. 2020, 34, 10148. [CrossRef]

4. Valacchi, G.; Sticozzi, C.; Pecorelli, A.; Cervellati, F.; Cervellati, C.; Maioli, E. Cutaneous responses to environmental stressors. Ann. N. Y. Acad. Sci. 2012, 1271, 75-81. [CrossRef] [PubMed]

5. Valejo Coelho, M.M.; Matos, T.R.; Apetato, M. The dark side of the light: Mechanisms of photocarcinogenesis. Clin. Dermatol. 2016, 34, 563-570. [CrossRef]

6. De Gruijl, F.R. Photocarcinogenesis: UVA vs. UVB radiation. Proc. Ski. Pharmacol. Appl. Ski. Physiol. 2002, 15, 316-320. [CrossRef] [PubMed]

7. Sample, A.; He, Y.Y. Mechanisms and prevention of UV-induced melanoma. Photodermatol. Photoimmunol. Photomed. 2018, 34, 13-24. [CrossRef] [PubMed]

8. Koh, H.K.; Geller, A.C.; Miller, D.R.; Grossbart, T.A.; Lew, R.A. Prevention and early detection strategies for melanoma and skin cancer: Current status. Arch. Dermatol. 1996, 132, 436-443. [CrossRef]

9. Woodby, B.; Penta, K.; Pecorelli, A.; Lila, M.A.; Valacchi, G. Skin Health from the Inside out. Annu. Rev. Food Sci. Technol. 2020, 11, 235-254. [CrossRef] [PubMed]

10. Packer, L.; Valacchi, G. Antioxidants and the response of skin to oxidative stress: Vitamin E as a key indicator. Ski. Pharmacol. Appl. Ski. Physiol. 2002, 15, 282-290. [CrossRef] [PubMed]

11. Young, A.R.; Claveau, J.; Rossi, A.B. Ultraviolet radiation and the skin: Photobiology and sunscreen photoprotection. J. Am. Acad. Dermatol. 2017, 76, S100-S109. [CrossRef] [PubMed]

12. Furukawa, J.Y.; Martinez, R.M.; Morocho-Jácome, A.L.; Castillo-Gómez, T.S.; Pereda-Contreras, V.J.; Rosado, C.; Velasco, M.V.R.; Baby, A.R. Skin impacts from exposure to ultraviolet, visible, infrared, and artificial lights-A review. J. Cosmet. Laser Ther. 2021, 23, 1-7. [CrossRef] [PubMed]

13. Watts, C.G.; Drummond, M.; Goumas, C.; Schmid, H.; Armstrong, B.K.; Aitken, J.F.; Jenkins, M.A.; Giles, G.G.; Hopper, J.L.; Mann, G.J.; et al. Sunscreen use and melanoma risk among young Australian adults. JAMA Dermatol. 2018, 154, 1001-1009. [CrossRef]

14. Grumezescu, A.M. Nanobiomaterials in Galenic Formulations and Cosmetics: Applications of Nanobiomaterials; William Andrew: Norwich, NY, USA, 2016; ISBN 9780323428910.

15. Pinnell, S.R. Cutaneous photodamage, oxidative stress, and topical antioxidant protection. J. Am. Acad. Dermatol. 2003, 48, 1-19. [CrossRef] [PubMed]

16. Heurung, A.R.; Raju, S.I.; Warshaw, E.M. Adverse reactions to sunscreen agents: Epidemiology, responsible irritants and allergens, clinical characteristics, and management. Dermatitis 2014, 25, 289-326. [CrossRef] [PubMed]

17. Peyrot, C.; Mention, M.M.; Brunissen, F.; Allais, F. Sinapic acid esters: Octinoxate substitutes combining suitable uv protection and antioxidant activity. Antioxidants 2020, 9, 782. [CrossRef]

18. Pambianchi, E.; Ferrara, F.; Pecorelli, A.; Woodby, B.; Grace, M.; Therrien, J.P.; Lila, M.A.; Valacchi, G. Blueberry Extracts as a Novel Approach to Prevent Ozone-Induced Cutaneous Inflammasome Activation. Oxid. Med. Cell. Longev. 2020, $2020,9571490$. [CrossRef] [PubMed]

19. Hoskin, R.; Pambianchi, E.; Pecorelli, A.; Grace, M.; Therrien, J.P.; Valacchi, G.; Lila, M.A. Novel spray dried algae-rosemary particles attenuate pollution-induced skin damage. Molecules 2021, 26, 3781. [CrossRef]

20. Huntley, A. Aromadermatology: Aromatherapy in the treatment and care of common skin conditions. Focus Altern. Complement. Ther. 2010, 12, 65-66. [CrossRef]

21. Lila, M.A.; Dunlap, K. Answering the call of the wild: Polyphenols in traditional therapeutic practice. In Recent Advances in Polyphenol Research; Quideau, S., de Freitas, V., Jess Reed, E., Eds.; Wiley and Sons Ltd.: Hoboken, NY, USA, 2020; pp. 49-67, Chapter 3.

22. Zujko, M.E.; Witkowska, A.M. Antioxidant potential and polyphenol content of selected food. Int. J. Food Prop. 2011, 14, 300-308. [CrossRef]

23. Kellogg, J.; Wang, J.; Flint, C.; Ribnicky, D.; Kuhn, P.; De Mejia, E.G.; Raskin, I.; Lila, M.A. Alaskan wild berry resources and human health under the cloud of climate change. J. Agric. Food Chem. 2010, 58, 3884-3900. [CrossRef] [PubMed]

24. Leduc, C.; Coonishish, J.; Haddad, P.; Cuerrier, A. Plants used by the Cree Nation of Eeyou Istchee (Quebec, Canada) for the treatment of diabetes: A novel approach in quantitative ethnobotany. J. Ethnopharmacol. 2006, 105, 55-63. [CrossRef] [PubMed] 
25. Boom, B.M.; Kari, P.R. Tanaina Plantlore. Dena'ina K'et'una. An ethnobotany of the Dena'ina Indians of Southcentral Alaska, 2nd ed. Brittonia 1990, 42, 163. [CrossRef]

26. Kellogg, J.; Higgs, C.; Lila, M.A. Prospects for commercialisation of an Alaska native wild resource as a commodity crop. J. Entrep. 2011, 20, 77-101. [CrossRef]

27. Valacchi, G.; Virgili, F.; Cervellati, C.; Pecorelli, A. OxInflammation: From subclinical condition to pathological biomarker. Front. Physiol. 2018, 9, 858. [CrossRef]

28. Grace, M.H.; Xiong, J.; Esposito, D.; Ehlenfeldt, M.; Lila, M.A. Simultaneous LC-MS quantification of anthocyanins and nonanthocyanin phenolics from blueberries with widely divergent profiles and biological activities. Food Chem. 2019, 277, 336-346. [CrossRef]

29. Grace, M.H.; Esposito, D.; Dunlap, K.L.; Lila, M.A. Comparative analysis of phenolic content and profile, antioxidant capacity, and anti-inflammatory bioactivity in wild alaskan and commercial vaccinium berries. J. Agric. Food Chem. 2014, 62, 4007-4017. [CrossRef]

30. International Agency for Research on Cancer. Review of Human Carcinogens; IARC Monographs on the Evaluation of Carcinogenic Risks to Humans; World Health Organization: Geneva, Switzerland, 2012; Volume 100 D, p. 341. ISBN 978-9283213215.

31. Signorini, C.; De Felice, C.; Durand, T.; Oger, C.; Galano, J.M.; Leoncini, S.; Pecorelli, A.; Valacchi, G.; Ciccoli, L.; Hayek, J. Isoprostanes and 4-hydroxy-2-nonenal: Markers or mediators of disease? Focus on rett syndrome as a model of autism spectrum disorder. Oxid. Med. Cell. Longev. 2013, 2013, 343824. [CrossRef]

32. Zhong, J.L.; Edwards, G.P.; Raval, C.; Li, H.; Tyrrell, R.M. The role of Nrf2 in ultraviolet A mediated heme oxygenase 1 induction in human skin fibroblasts. Photochem. Photobiol. Sci. 2010, 9, 18-24. [CrossRef]

33. Wlaschek, M.; Tantcheva-Poór, I.; Naderi, L.; Ma, W.; Schneider, L.A.; Razi-Wolf, Z.; Schüller, J.; Scharffetter-Kochanek, K. Solar UV irradiation and dermal photoaging. J. Photochem. Photobiol. B Biol. 2001, 63, 41-51. [CrossRef]

34. Sandilands, A.; Sutherland, C.; Irvine, A.D.; McLean, W.H.I. Filaggrin in the frontline: Role in skin barrier function and disease. J. Cell Sci. 2009, 122, 1285-1294. [CrossRef] [PubMed]

35. Steven, A.C.; Steinert, P.M. Protein composition of cornified cell envelopes of epidermal keratinocytes. J. Cell Sci. 1994, 107, 693-700. [CrossRef] [PubMed]

36. Meyer, T.; Stockfleth, E. Light and Skin. Curr. Probl. Dermatol. 2021, 55, 53-61. [CrossRef] [PubMed]

37. Pattison, D.I.; Davies, M.J. Actions of ultraviolet light on cellular structures. EXS 2006, 96, 131-157.

38. Yaar, M. Clinical and histological features of intrinsic versus extrinsic skin aging. In Skin Aging; Springer: Berlin/Heidelberg, Germany, 2006; pp. 9-21. ISBN 3540244433.

39. Bianchini Silva, L.S.; Perasoli, F.B.; Carvalho, K.V.; Vieira, K.M.; Paz Lopes, M.T.; Bianco de Souza, G.H.; Henrique dos Santos, O.D.; Freitas, K.M. Melaleuca leucadendron (L.) L. flower extract exhibits antioxidant and photoprotective activities in human keratinocytes exposed to ultraviolet B radiation. Free Radic. Biol. Med. 2020, 159, 54-65. [CrossRef]

40. Azevedo Martins, T.E.; Sales de Oliveira Pinto, C.A.; Costa de Oliveira, A.; Robles Velasco, M.V.; Gorriti Guitiérrez, A.R.; Cosquillo Rafael, M.F.; Paúl Huamaní Tarazona, J.; Retuerto-Figueroa, M.G. Contribution of topical antioxidants to maintain healthy skin-A review. Sci. Pharm. 2020, 88, 27. [CrossRef]

41. Morocho-Jácome, A.L.; Freire, T.B.; de Oliveira, A.C.; de Almeida, T.S.; Rosado, C.; Velasco, M.V.R.; Baby, A.R. In vivo SPF from multifunctional sunscreen systems developed with natural compounds-A review. J. Cosmet. Dermatol. 2021, 20, 729-737. [CrossRef]

42. Pop, T.D.; Diaconeasa, Z. Recent advances in phenolic metabolites and skin cancer. Int. J. Mol. Sci. 2021, 22, 9707. [CrossRef]

43. Fivenson, D.; Sabzevari, N.; Qiblawi, S.; Blitz, J.; Norton, B.B.; Norton, S.A. Sunscreens: UV filters to protect us: Part 2-Increasing awareness of UV filters and their potential toxicities to us and our environment. Int. J. Women's Dermatol. 2021, 7, 45-69. [CrossRef]

44. Dreher, F.; Maibach, H. Protective effects of topical antioxidants in humans. Curr. Probl. Dermatol. 2001, 29, 157-164.

45. Podda, M.; Grundmann-Kollmann, M. Low molecular weight antioxidants and their role in skin ageing. Clin. Exp. Dermatol. 2001, 26, 578-582. [CrossRef]

46. Wang, X.; Heraud, S.; Thepot, A.; Dos Santos, M.; Luo, Z. The whitening properties of the mixture composed of pomegranate, osmanthus and olive and the protective effects against ultraviolet deleterious effects. Clin. Cosmet. Investig. Dermatol. 2021, 14, 561-573. [CrossRef]

47. Valacchi, G.; Pagnin, E.; Corbacho, A.M.; Olano, E.; Davis, P.A.; Packer, L.; Cross, C.E. In vivo ozone exposure induces antioxidant/stress-related responses in murine lung and skin. Free Radic. Biol. Med. 2004, 36, 673-681. [CrossRef] [PubMed]

48. Nisar, M.F.; Parsons, K.S.G.; Bian, C.X.; Zhong, J.L. UVA irradiation induced heme oxygenase-1: A novel phototherapy for morphea. Photochem. Photobiol. 2015, 91, 210-220. [CrossRef] [PubMed]

49. Glady, A.; Tanaka, M.; Moniaga, C.S.; Yasui, M.; Hara-Chikuma, M. Involvement of NADPH oxidase 1 in UVB-induced cell signaling and cytotoxicity in human keratinocytes. Biochem. Biophys. Reports 2018, 14, 7-15. [CrossRef]

50. Pecorelli, A.; Woodby, B.; Prieux, R.; Valacchi, G. Involvement of 4-hydroxy-2-nonenal in pollution-induced skin damage. BioFactors 2019, 45, 536-547. [CrossRef] [PubMed]

51. Irvine, A.D.; McLean, W.H.I. Breaking the (un)sound barrier: Filaggrin is a major gene for atopic dermatitis. J. Investig. Dermatol. 2006, 126, 1200-1202. [CrossRef] 
52. Palmer, C.N.A.; Irvine, A.D.; Terron-Kwiatkowski, A.; Zhao, Y.; Liao, H.; Lee, S.P.; Goudie, D.R.; Sandilands, A.; Campbell, L.E.; Smith, F.J.D.; et al. Common loss-of-function variants of the epidermal barrier protein filaggrin are a major predisposing factor for atopic dermatitis. Nat. Genet. 2006, 38, 441-446. [CrossRef]

53. Sandilands, A.; O’Regan, G.M.; Liao, H.; Zhao, Y.; Terron-Kwiatkowski, A.; Watson, R.M.; Cassidy, A.J.; Goudie, D.R.; Smith, F.J.D.; McLean, W.H.I.; et al. Prevalent and rare mutations in the gene encoding filaggrin cause ichthyosis vulgaris and predispose individuals to atopic dermatitis. J. Investig. Dermatol. 2006, 126, 1770-1775. [CrossRef]

54. Kim, B.E.; Leung, D.Y.M. Significance of skin barrier dysfunction in atopic dermatitis. Allergy Asthma Immunol. Res. 2018, 10, 207-215. [CrossRef]

55. Egawa, G.; Kabashima, K. Barrier dysfunction in the skin allergy. Allergol. Int. 2018, 67, 3-11. [CrossRef] [PubMed]

56. Lee, J.M.; Johnson, J.A. An important role of Nrf2-ARE pathway in the cellular defense mechanism. J. Biochem. Mol. Biol. 2004, 37, 139-143. [CrossRef] [PubMed]

57. Li, W.; Khor, T.O.; Xu, C.; Shen, G.; Jeong, W.S.; Yu, S.; Kong, A.N. Activation of Nrf2-antioxidant signaling attenuates NFkBinflammatory response and elicits apoptosis. Biochem. Pharmacol. 2008, 76, 1485-1489. [CrossRef] [PubMed] 